\title{
The effect of rotational speed variation on the static pressure in the centrifugal pump (part 1)
}

\author{
Dr. Mohammed Ali Mahmood Hussein \\ Al-Rafidain University Collage,
}

\begin{abstract}
The current investigation is aimed to simulate the three-dimensional complex internal flow in a centrifugal pump impeller with five twisted blades by using specialized computational fluid dynamics (CFD) software ANSYS /FLUENT 14code with a standard $k$ - $\varepsilon$ two-equation turbulence model.

A single blade passage will be modeled to give more accurate results for static pressure contours on (blade, hub, and shroud). The potential consequences of static pressure associated with operating a centrifugal compressor in variable rotation speed.

A numerical three-dimensional, through flow calculations to predict static pressure through a centrifugal pump were presented to examined the effect of rotational speed variation on the static pressure of the centrifugal pump. The contours of the static pressure of the blade, hub, and shroud indicates negative low static pressure in the suction side at high rotational speed (over operation limits) and the static pressure increases gradually until reach maximum value at the leading edge $\left(6 \times 10^{5} \mathrm{~Pa}\right)$ of the blade.
\end{abstract}

Keywords: CFD, Centrifugal pump, $3 D$ numerical simulation

\section{Introduction:-}

Computational fluid dynamics (CFD) analysis is being increasingly applied in the design of centrifugal pumps. With the aid of the CFD approach, the complex internal flows in water pump impellers, which are not fully understood yet, can be well predicted, to speed up the pump design procedure. Thus, CFD is an very important tool for pump designers. The use of CFD tools in turbo machinery industry is quite common today. Many tasks can numerically be solved much faster and cheaper than by means of experiments.

The complex flow pattern inside a centrifugal pump is strong three-dimensional with recirculation flows at inlet and exit, flow separation, cavitation's, and so on. The curvature of the blades and the rotational system have great influence on the flow field.

Dr. Jalal M. Jalil ,et al. [1] developed a solution method to obtain three-dimensional velocity and pressure distribution within a centrifugal pump impeller. The method is based on solving fully elliptic partial differential equations for the conservation of mass and momentum by finite difference method to convert them into algebraic equations. The effect of turbulence introduced using a certain algebraic model based on modified Prandtl's mixing length theorem, Liu et al. [2], Zhou, W. et al, [3] have used a CFD code to study threedimensional turbulent flow through water-pump impellers during design and off-design conditions. Three different types of centrifugal pumps were considered in this simulation. One pump had four straight blades and the other two had six twisted blades. It was found that pumps having six twisted blades were better than those for pumps with straight blades, which suggests that the efficiency of pumps with twisted blades will also be higher than that of pumps with straight blades Akhras et al. [4], and Pedersen et al. [5] have made the measurement on centrifugal pumps and reported that impeller flow separation was observed on blade surface at off-design flow rate as compared to smooth flow within the impeller passage at design point. The numerical simulation made by Heilmann and Siekmann [6] and Majidi and Siekmann [7] showed the strong secondary flow in volute and circular casings of centrifugal pumps. Ziegler et al. [8], Shi and Tsukamoto [9], Shum et al. [10], and Akhras et al. [11] studied impeller diffuser interaction on the pump performance and showed that a strong pressure fluctuation is due to the unsteadiness of the flow shedding from impeller exit.

Hong and Kang [12] and Hagelstein et al. [13] investigated the flow field at the impeller exit and volute separately to study the pressure distribution due to impeller-volute interaction. Traditional method to design the centrifugal pump is mainly based on the steady-state theory, empirical correlation, combination of model testing, and engineering experience [14]. However, to further improve the pump performance for design and offdesign operating conditions, it will become extremely difficult. Complex flow field such as the boundary layer separation, vortex dynamics, interactions between the impeller and diffuser are difficult to control due to the rotating and stationary components.

Zhang et al. $[15,16]$ found that jet-wake structure occurs near the outlet of the impeller and it is independent of flow rate and locations. Byskov et al. [17] investigated a six-bladed impeller with shroud by using the large eddy simulation (LES) at design and off-design conditions. At design load, the flow field inside the impeller is smooth and with no significant separation. At quarter design load, a steady nonrotating stall 
phenomenon is observed in the entrance and a relative eddy is developed in the remaining of the passage. Gu et al. [18] also investigated the volute/diffuser interaction of a single stage centrifugal compressor at design point and off-design. At higher flow rate, a twin vortex structure is formed downstream of the passage.

The recirculation and the twin vortex structure are attributed increase of the total pressure losses at offdesign conditions. Hence with the advancing of computer power, significant improvement of numerical algorithms and more reliable CFD codes, it can be seen that there is an increasing trend of applying numerical methods to study the complex flow

\section{Governing equations:-}

Casting of The three-dimensional and incompressible flow in the pumps can be described with the conservations laws of movement and mass in cylindrical coordinates for radial (r), angular $(\theta)$ and axial (z) directions. In terms of the divergence theorem, the continuity equation or conservation mass, Continuity: [17]:

$$
\nabla \cdot \vec{V}=0
$$

Momentum:

$$
\rho[\vec{V} \cdot(\nabla \cdot \vec{V})]=-\nabla P+\mu_{e f}\left(\nabla^{2} \cdot \vec{V}\right)+\vec{F}
$$

where: $\rho=$ density fluid

$\vec{V}=$ vector velocity absolute

$\mu_{\text {ef }}=$ viscosity effective fluid

$\mathrm{P}=$ pressure body forces

$\mathrm{Fi}$ = the additional sources of momentum

Since the momentum equations are considered in a relative reference frame associated to the rotor blade, the Coriolis force and centrifugal forces are added as a momentum source term:

$$
F_{i}=F_{i, c o}+F_{i, c e}
$$

Where

$$
\begin{aligned}
& F_{i, c o}=-2 \varepsilon_{i j k} \omega_{j} u_{k} \\
& F_{i, c e}=-\omega_{j} \omega_{i} x_{j}+\omega_{j} \omega_{j} x_{i}
\end{aligned}
$$

$\omega_{\mathrm{i}}$ : is angular velocity

$\varepsilon_{\mathrm{ijk}}$ is Levi-Civita third order tensor

\section{Turbulence model}

The left side term in Equation (2) represents the convective acceleration. The right side terms represent the pressure gradient, the viscous effects and the source terms respectively. The turbulence model chosen was the k- $\varepsilon$ model due to its stability, widespread application in commercial softwares and robustness. The k- $\varepsilon$ model and its extensions resolve the partial differential equations for turbulent kinetic energy $\mathrm{k}$ and the dissipation rate $\varepsilon$ as shown by the Equations (6) and (7):

$$
\begin{gathered}
\rho[\vec{V} \cdot(\nabla \cdot k)]=\nabla\left(\Gamma_{c} \nabla k\right)+P-\rho \varepsilon \\
\rho[\vec{V} \cdot(\nabla \cdot \varepsilon)]=\nabla\left(\Gamma_{\varepsilon} \nabla \varepsilon\right)+C_{\varepsilon 1} \frac{\varepsilon P}{k}-C_{\varepsilon 2} \frac{\rho \varepsilon^{2}}{k}
\end{gathered}
$$

Where the diffusion coefficients are given by

$$
\begin{aligned}
& \Gamma_{k}=\mu+\frac{\mu_{t}}{\sigma_{k}} \\
& \Gamma_{\iota}=\mu+\frac{\mu_{t}}{\sigma_{\varepsilon}}
\end{aligned}
$$


The turbulence viscosity, $\mu \mathrm{t}$ can be derived from Eq. (9) and (10), to link to the turbulence kinetic energy and dissipation via the relation

$$
\mu_{t}=C_{\mu} \rho \frac{K^{2}}{\varepsilon}
$$

And

$$
\begin{aligned}
& \varepsilon=\frac{k^{\frac{3}{2}}}{l_{t}} \\
& p_{k}=\mu_{t} \nabla U\left(\nabla U+\nabla U^{T}\right)-\frac{2}{3} \nabla U\left(\mu_{t} \nabla U+\rho k\right)
\end{aligned}
$$

$\mathrm{P}_{\mathrm{k}}$ is the term for the production of turbulence due to viscous forces Parameter values considered in the simulations are presented in the table 1 .

Table 1: Parameters for modeling the $k-\varepsilon$ model

\begin{tabular}{|l|l|l|l|l|}
\hline$C_{\mu}$ & $C_{\varepsilon 1}$ & $C_{\varepsilon 2}$ & $\sigma_{K}$ & $\sigma_{\varepsilon}$ \\
\hline 0.09 & 1.45 & 1.9 & 1 & 1.03 \\
\hline
\end{tabular}

Equations (1), (2), (6), and (7) form a closed set of nonlinear partial differential equations governing the fluid motion.

All the previous equations are valid both for the impeller and for the diffuser; however the rotational forces in the source terms will only apply for the impeller in the movement equation as a result of Coriolis forces and centrifugal forces. The transport equations associated with the given boundaries conditions describing the internal flow in centrifugal pump are solved by the (ANSYS-14) code.

\section{Single passage, Geometry and Grid}

With the three-dimensional model there is a useful approach for investigation of flow behavior in different parts of pump. Figure 1shows the centrifugal pump geometry and structured grid generated of single blade passage (blade mesh, hub mesh, and shroud mesh). Problem consists of a five blade centrifugal pump operating at $2100 \mathrm{rpm}$. The working fluid is water and flow is assumed to be steady and incompressible .Due to rotational periodicity a single blade passage will be modeled. Table (2) Operating conditions

\begin{tabular}{|l|l|}
\hline Description & Value \\
\hline Density of fluid & $1000 \mathrm{~kg} / \mathrm{m}^{3}$ \\
\hline Viscosity & $0.0017 \mathrm{~kg} / \mathrm{m} * \mathrm{~s}$ \\
\hline Rotational speed & $2100 \mathrm{rpm}$ \\
\hline
\end{tabular}

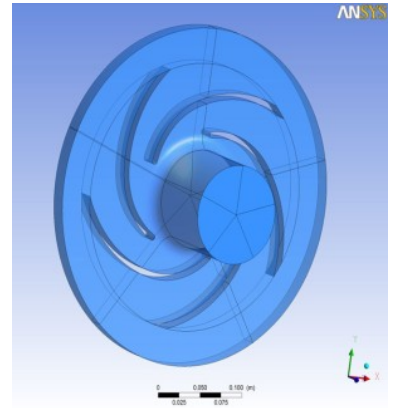

(a) Centrifugal pump geometry
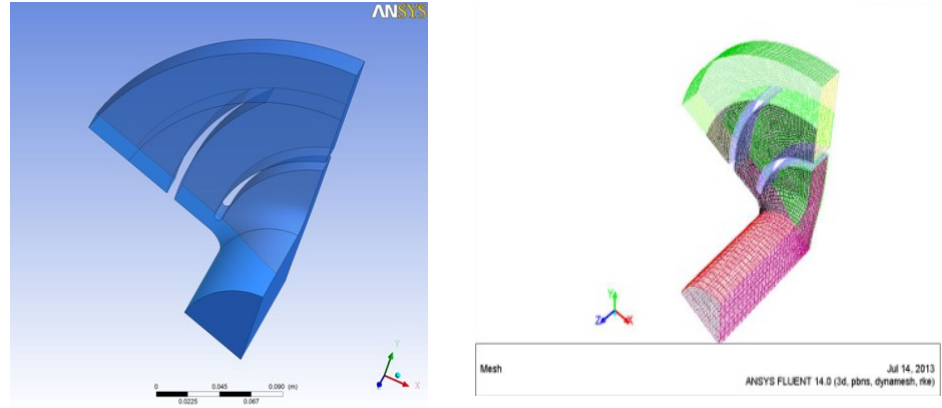

(b) Single blade passage geometry and mesh 


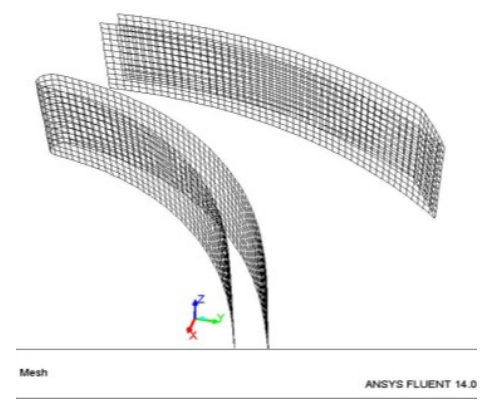

(c) Blade mesh

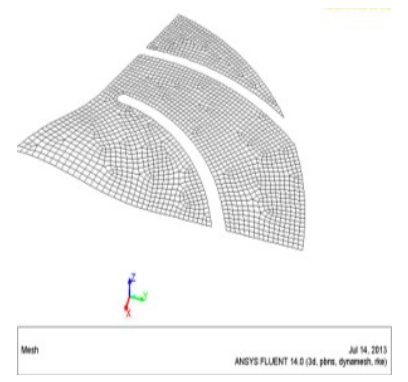

(d) Hub Mesh

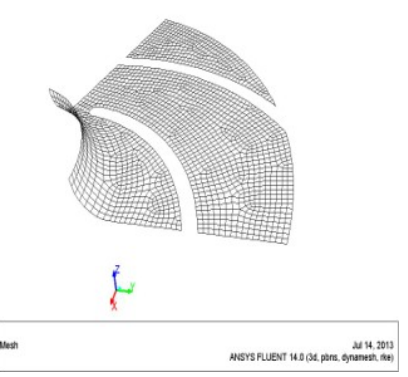

(e)Shroud mesh

Figure (1) (a,b.c.d.e) Shows the Centrifugal pump and generated mesh

\section{Results And Discussions}

A numerical three-dimensional, through flow calculations to predict static pressure through a centrifugal pump were presented to examined the effect of rotational speed variation on the static pressure in the centrifugal pump . Figures $(2,3 \& 4)$ represent the contours of the static pressure of the blade, hub, and shroud at rotational speed of $1800 \mathrm{rpm}$ the flow indicates low static pressure $\left(2.56 \times 10^{5} \mathrm{~Pa}\right)$ in the suction side and the static pressure increases gradually until reach maximum value at the leading edge $\left(6 \times 10^{5} \mathrm{~Pa}\right)$.
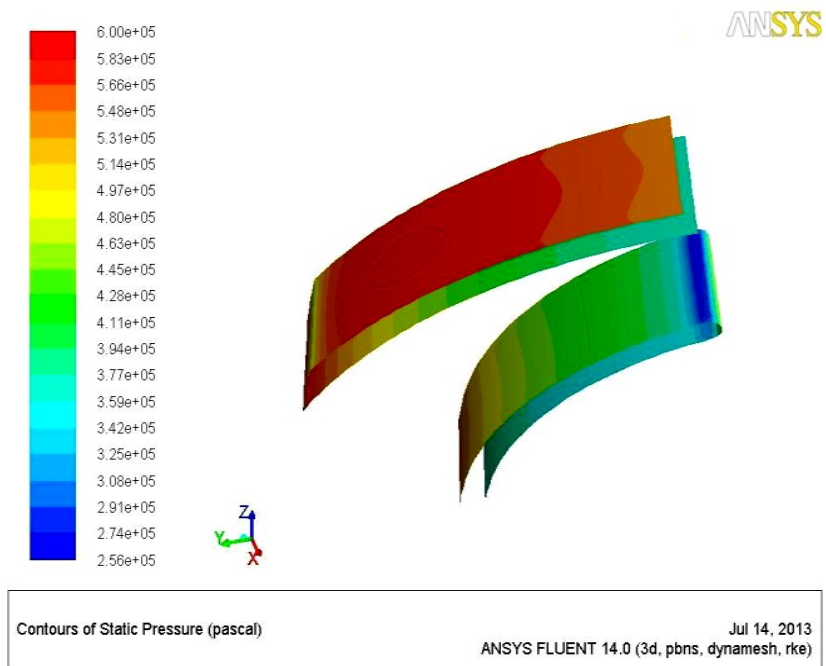

Contours of Static Pressure (pascal)

ANSYS FLUENT 14.0 (3d, pbns, dynamesh, rh

Figure(2) Static pressure contours in (Z-Y)plane of blade at 1800rpm
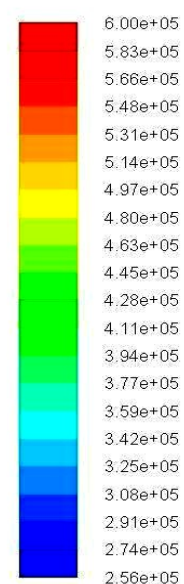

$00 e^{+05}$

$83 \mathrm{e}+05$

$5.31 e^{+05}$

$5.14 \mathrm{e}+05$
$4.97 \mathrm{e}+05$

$480+05$

$4.63 e+05$

$45 e+05$

$11 \mathrm{e}+05$

94 e+05

$377 \mathrm{e}+05$

$590+05$

$42 \mathrm{e}+05$

$2.91 \mathrm{e}+05$

$2.74 \mathrm{e}+05$

$2.56 \mathrm{e}+05$

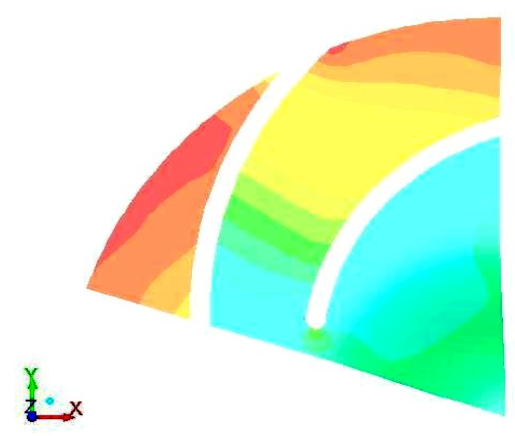

Contours of Static Pressure (pascal)

Jul 14,2013
namesh, rke)

Figure(3) Static pressure contours in (X-Y)plane of hub at 1800rpm 


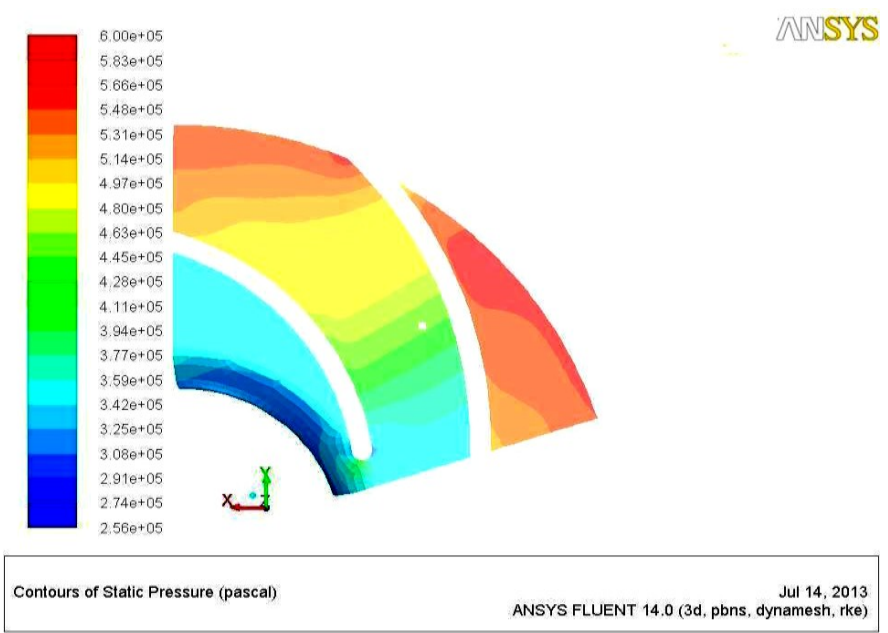

Figure(4) Static pressure contours in (X-Y)plane of shroud at 1800rpm

Figures $(5,6 \& 7)$ represent the contours of the static pressure of the blade, hub, and shroud at rotational speed of $1900 \mathrm{rpm}$ the flow indicates low static pressure $\left(2.42 \times 10^{5} \mathrm{~Pa}\right)$ in the suction side which is less than above case that mean increases in flow rate and the static pressure increases gradually until reach maximum value at the leading edge $\left(6 \times 10^{5} \mathrm{~Pa}\right)$.

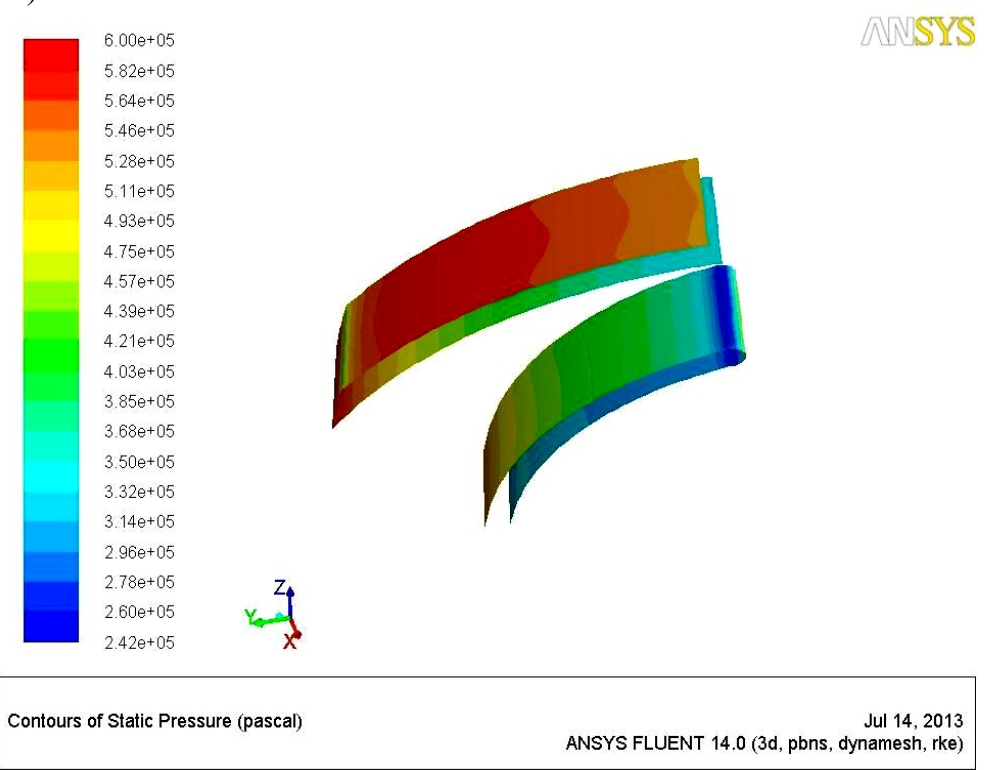

Figure(5) Static pressure contours in (Z-Y)plane of blade at 1900rpm

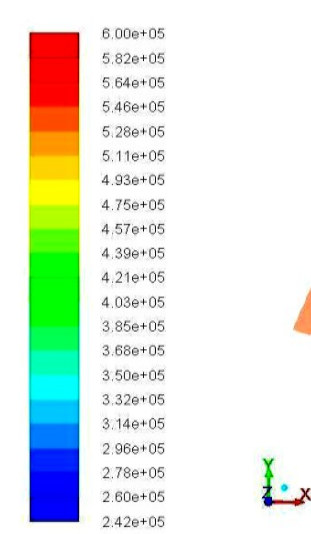

ANASTYS

Contours of Static Pressure (pascal)

Jul 14, 2013

Figure(6) Static pressure contours in (X-Y)plane of hub at 1900rpm 


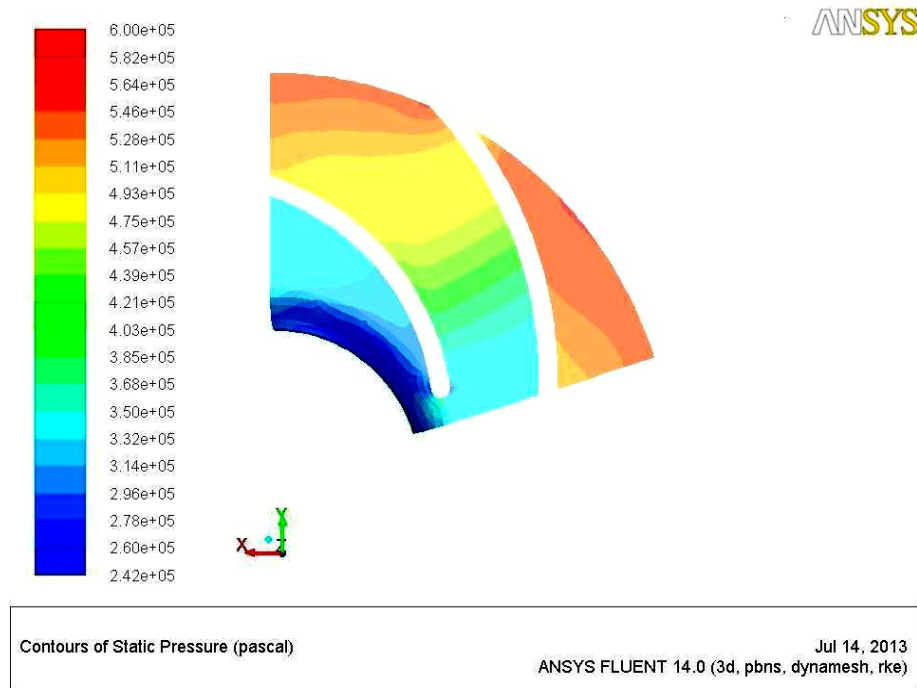

Figure(7) Static pressure contours in (X-Y)plane of shroud at 1900rpm

Figures $(8,9 \& 10)$ represent the contours of the static pressure of the blade, hub, and shroud at rotational speed of 2000rpm the flow indicates low static pressure $\left(1.81 \times 10^{5} \mathrm{~Pa}\right)$ in the suction side which is less than above case that mean increases in flow rate and the static pressure increases gradually until reach maximum value at the leading edge $\left(6 \times 10^{5} \mathrm{~Pa}\right)$.

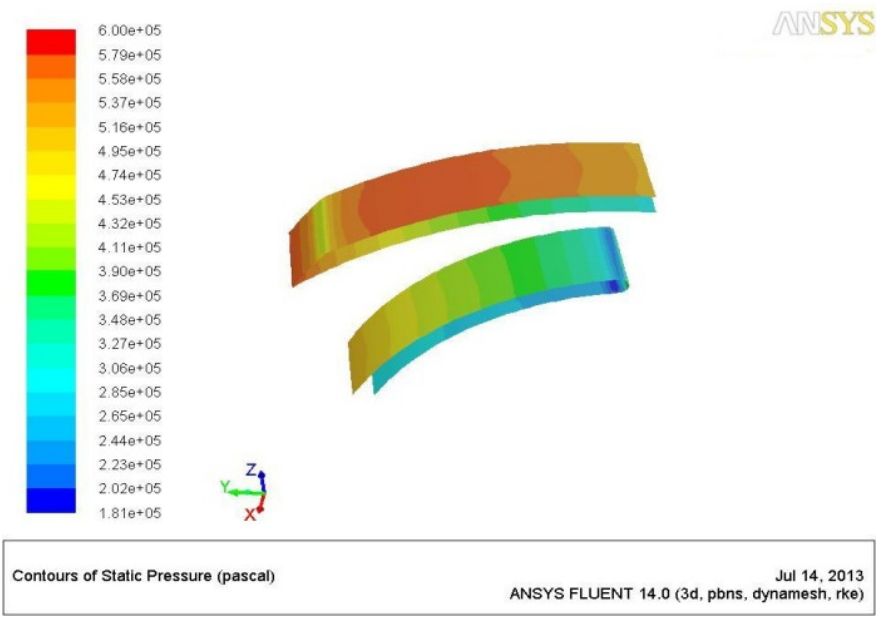

Figure(8) Static pressure contours in (Z-Y)plane of blade at 2000rpm

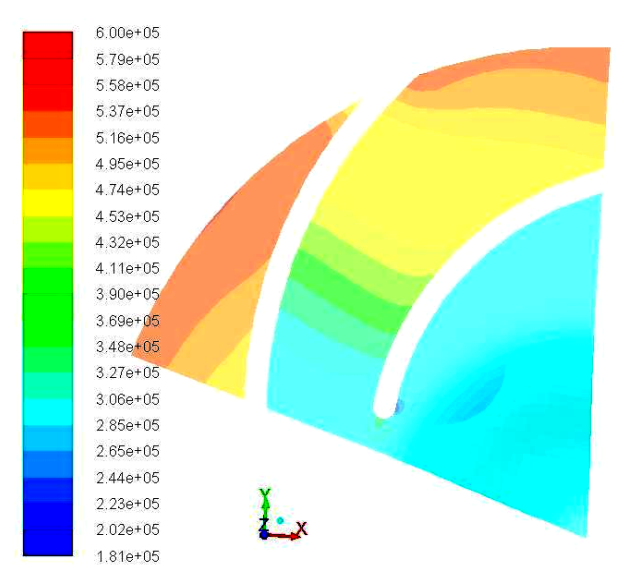

ANSSYS

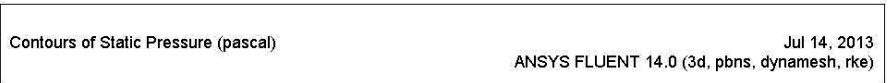

Figure(9) Static pressure contours in (X-Y)plane of hub at 2000rpm 

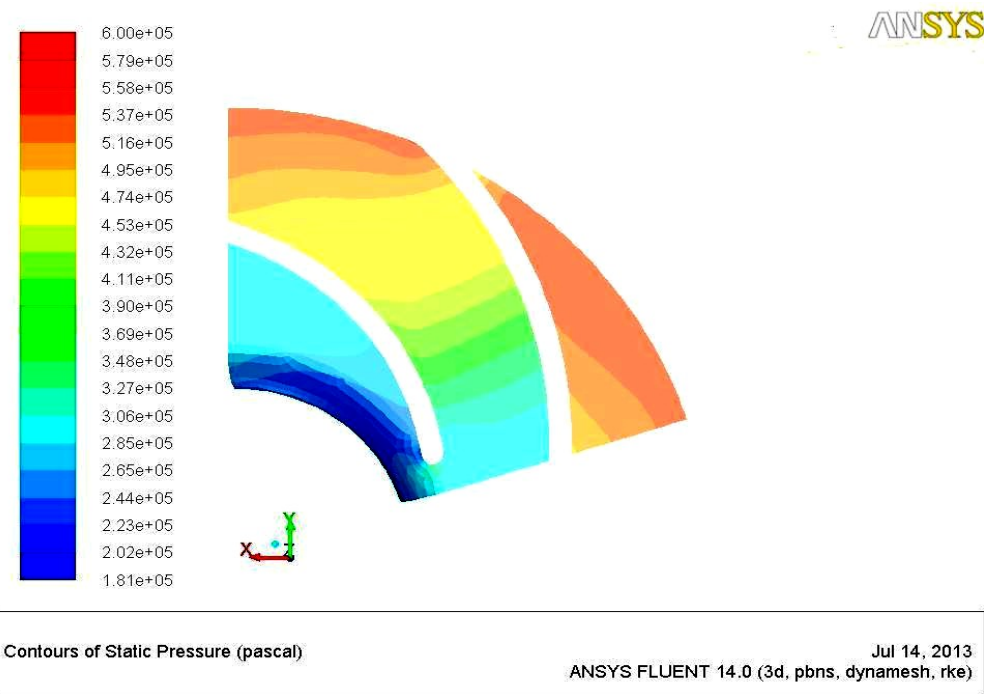

Contours of Static Pressure (pascal)

ANSYS FLUENT 14.0 (3d, pbns, dynamesh, rke)

Figure(10) Static pressure contours in (X-Y)plane of shroud at 2000rpm

Figures from (11) to (16) represent the contours of the static pressure of the blade, hub, and shroud at rotational speed of $2100 \mathrm{rpm}$ and $2200 \mathrm{rpm}$ which is the operation conditions (design point) flow indicates low static pressure $\left(3.38 \times 10^{4} \mathrm{~Pa}\right)$ in the suction side which is less than above case that mean increases in flow rate (optimum value) and the static pressure increases gradually until reach maximum value at the leading edge $\left(6 \times 10^{5} \mathrm{~Pa}\right)$.

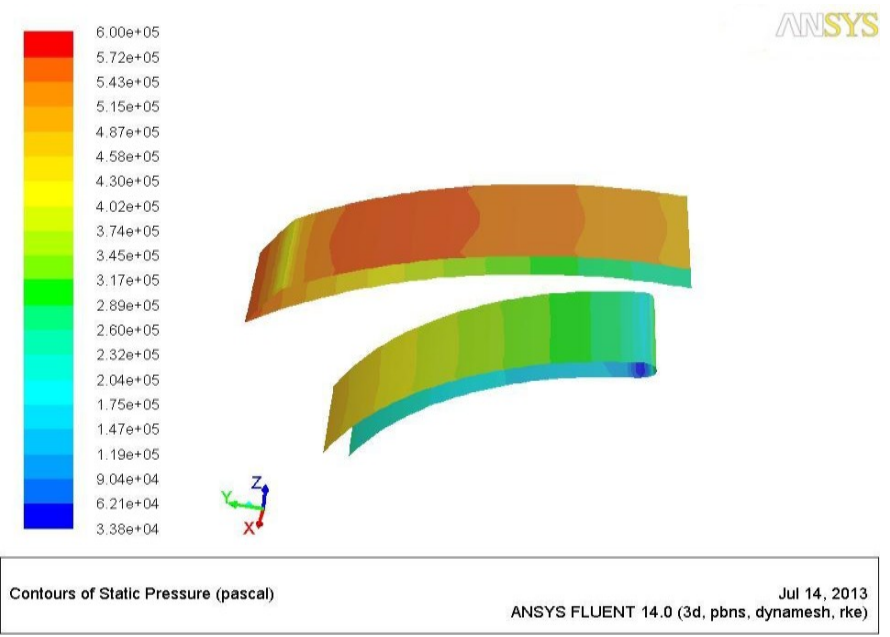

Figure(11) Static pressure contours in (Z-Y)plane of blade at 2100rpm

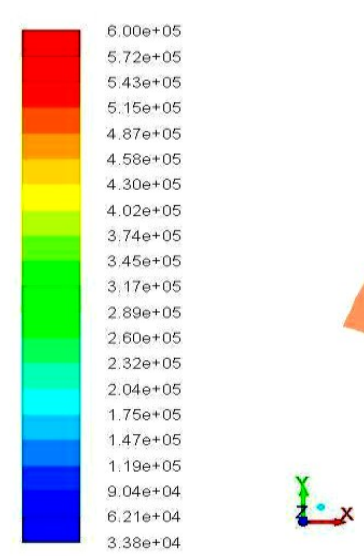

ANNSIYS

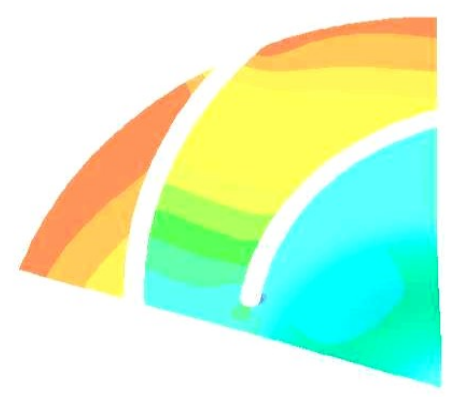

Contours of Static Pressure (pascal)

Jul 14, 2013

Figure(12) Static pressure contours in (X-Y)plane of hub at 2100rpm 


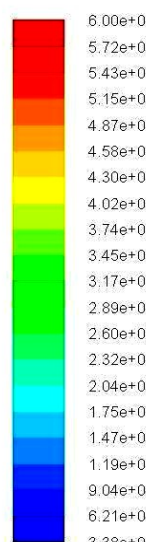

$00+05$

$5.720+05$

$5.43 e+05$

$4.580+05$

$430 \mathrm{e}+05$

$4.02 \mathrm{e}+05$
$374 \mathrm{e}+05$

$45 \theta+05$

$2.890+05$

$2.04 \mathrm{e}+05$

$750+05$

$0.04 \mathrm{e}+04$

$21 \mathrm{e}+04$
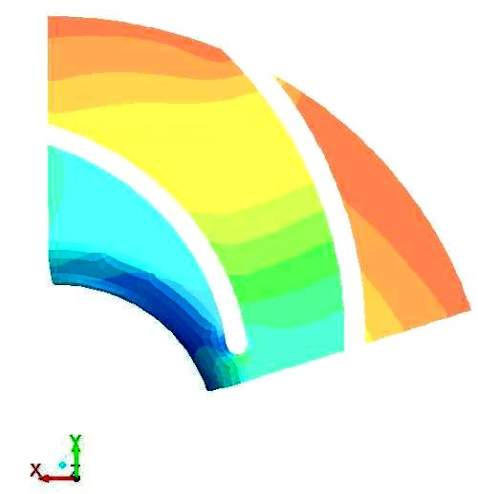

ANISYYS

Contours of Static Pressure (pascal)

ANSYS FLUENT 14.0 (3d, pbns, dynamesh, rke)

Figure(13) Static pressure contours in (X-Y)plane of shroud at 2100rpm

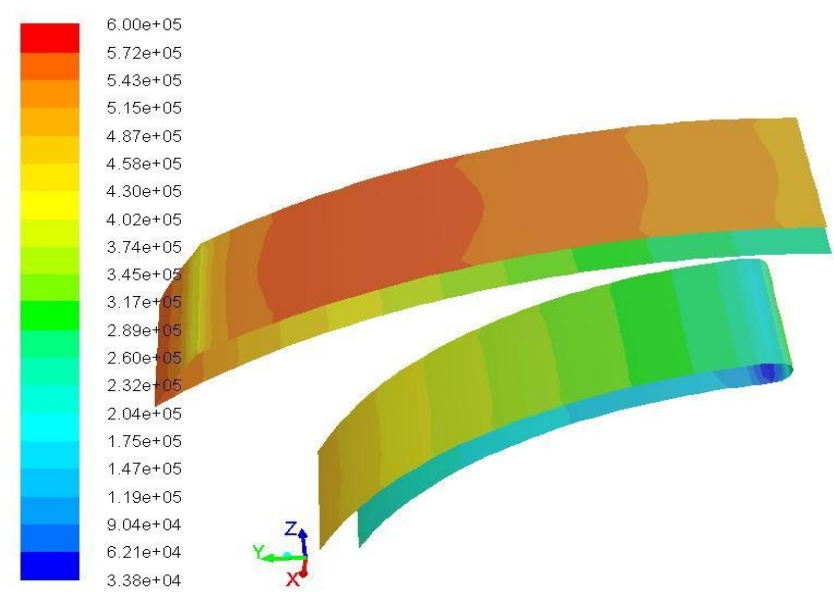

Contours of Static Pressure (pascal)

ANSYS FLUENT 14.0 (3d, pbns, dynamesh, rke)

Figure(14) Static pressure contours in (Z-Y)plane of blade at 2200rpm

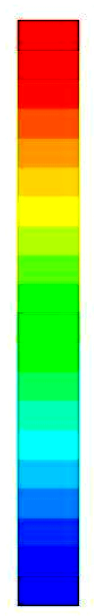

$6.00 e+05$
$5.72 e+05$
$5.43 e+05$
$5.15 e+05$
$4.87 e+05$
$4.58 e+05$
$4.30 e+05$
$4.02 e+05$
$3.74 e+05$
$3.45 e+05$
$3.17 e+05$
$2.89 e+05$
$2.60 e+05$
$2.32 e+05$
$2.04 e+05$
$1.75 e+05$
$1.47 e+05$
$1.19 e+05$
$9.04 e+04$
$6.21 e+04$
$3.38 e+04$

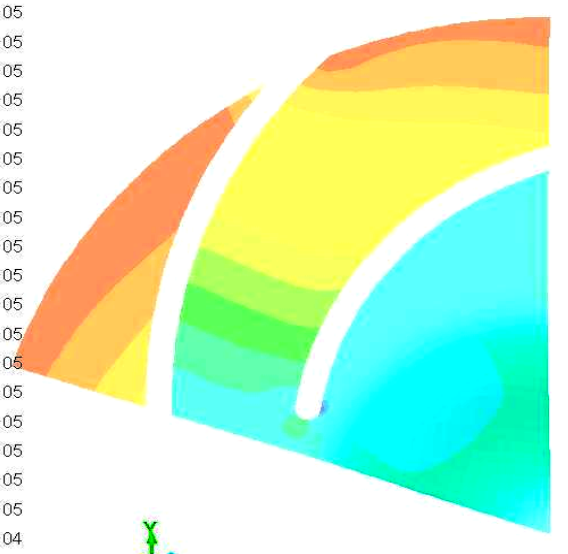

ANSTYS

$38 \mathrm{e}+04$

Figure(15) Static pressure contours in (X-Y)plane of hub at 2200rpm 


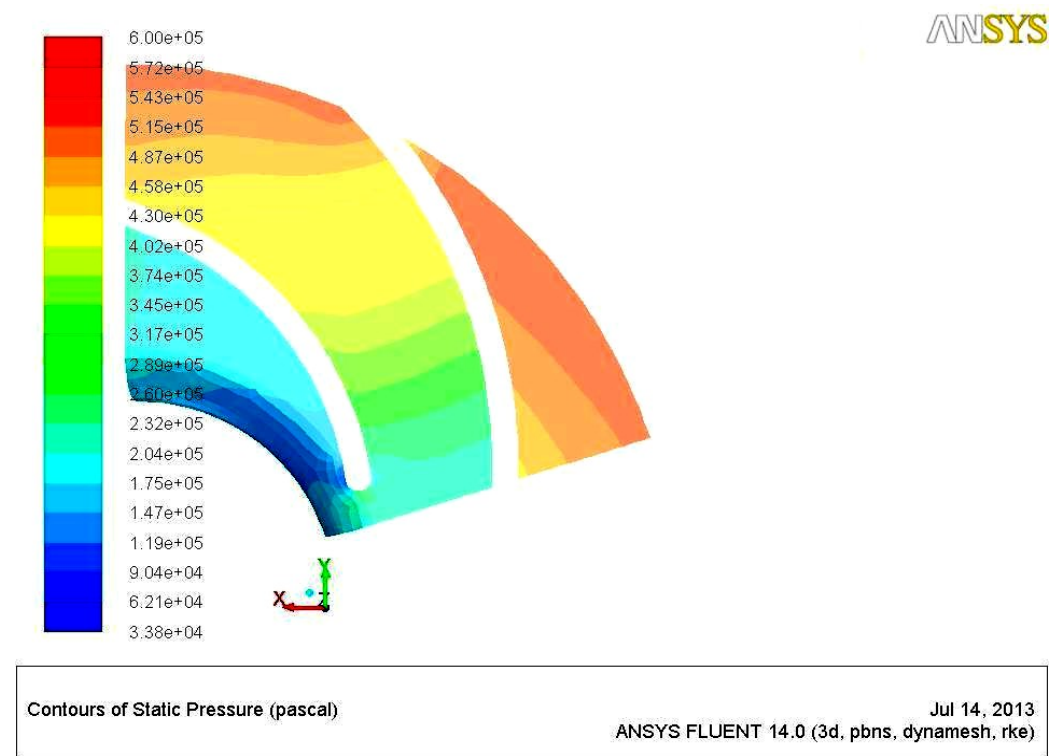

Figure(16) Static pressure contours in (X-Y)plane of shroud at 2200rpm

Figures from (17) to (22) represent the contours of the static pressure of the blade, hub, and shroud at rotational speed of 2300rpm and $2400 \mathrm{rpm}$ which is over the operation conditions (overload) flow indicates low negative static pressure $\left(-1.81 \times 10^{4} \mathrm{~Pa}\right)$ in the suction side which is less than above case that mean under normal operation, the wake regions are sufficiently small and of reasonably limited pressure magnitude (i.e., the difference between the static pressure in the wake region and the static pressure in the core flow is small). Therefore, there is not enough force or "delta pressure" to cause any difficulties. However, if the difference between the static pressure in the core flow and static pressure in the secondary zone and blade wakes is higher. The static pressure increases gradually until reach maximum value at the leading edge $\left(6 \times 10^{5} \mathrm{~Pa}\right)$. A fluid vaporizes when its pressure becomes too low, or its temperature too high. All centrifugal pumps have a required head (pressure) at the suction side of the pump to prevent this vaporization. This head requirement is supplied to us by the pump manufacturer but when the centrifugal pump work under high rotation speed over the design limits as in case study in the present work the pressure in the suction side became negative pressure causes cavitation (Cavitation means that cavities or bubbles are forming in the liquid that we're pumping. These cavities form at the low pressure or suction side of the pump), causing several things to happen all at once:

- The cavities or bubbles will collapse when they pass into the higher regions of pressure, causing noise, vibration, and damage to many of the components.

- We experience a loss in capacity.

- The pump can no longer build the same head (pressure)

- The pump's efficiency drops.

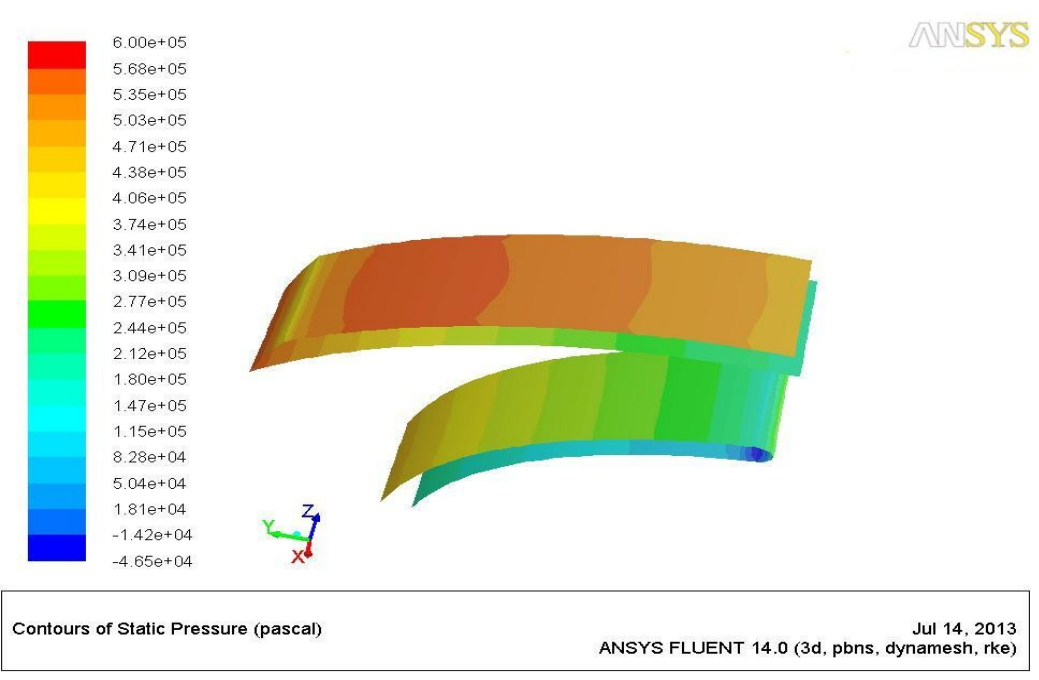

Figure(17) Static pressure contours in (Z-Y)plane of blade at 2300rpm 


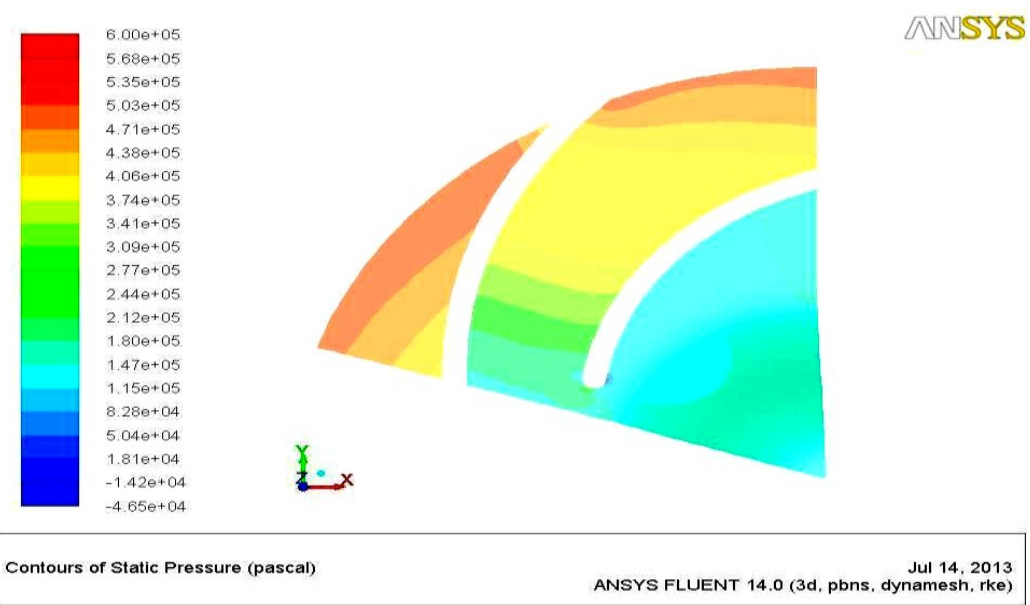

Figure(18) Static pressure contours in (X-Y)plane of hub at 2300rpm

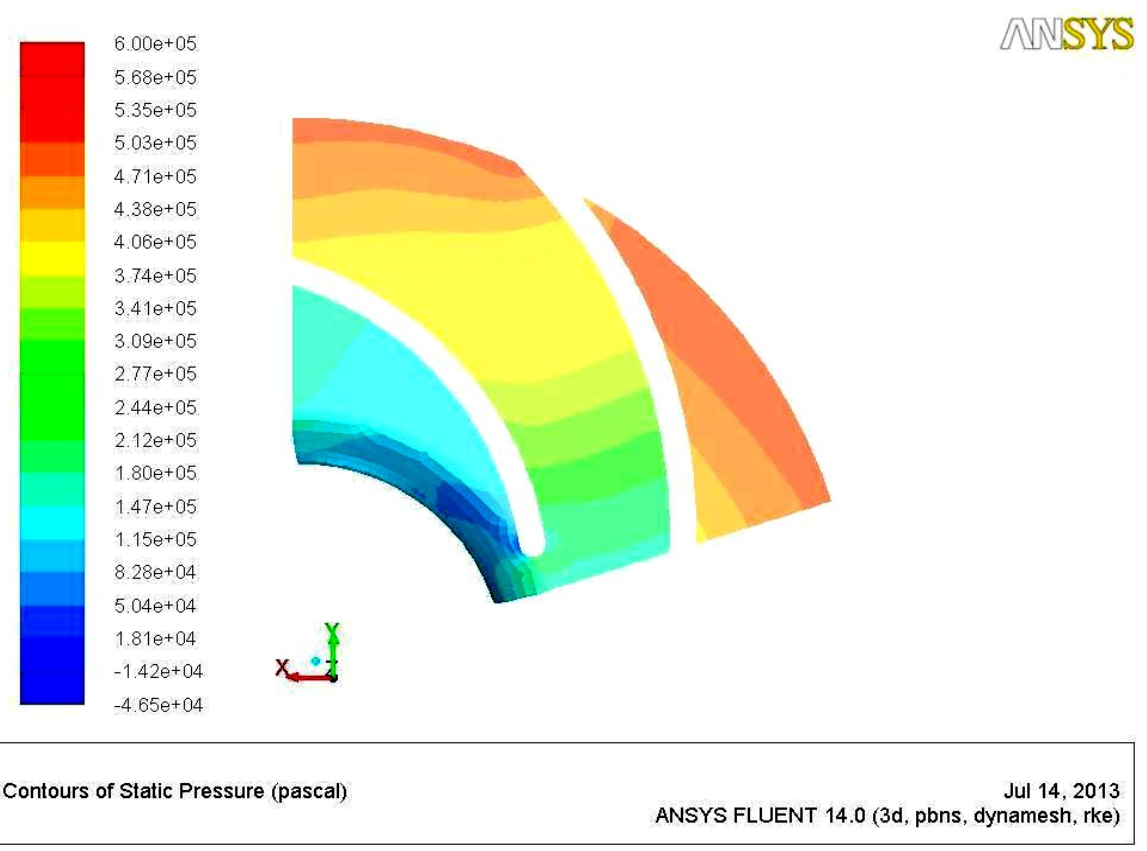

Figure(19) Static pressure contours in (X-Y)plane of shroud at 2300rpm

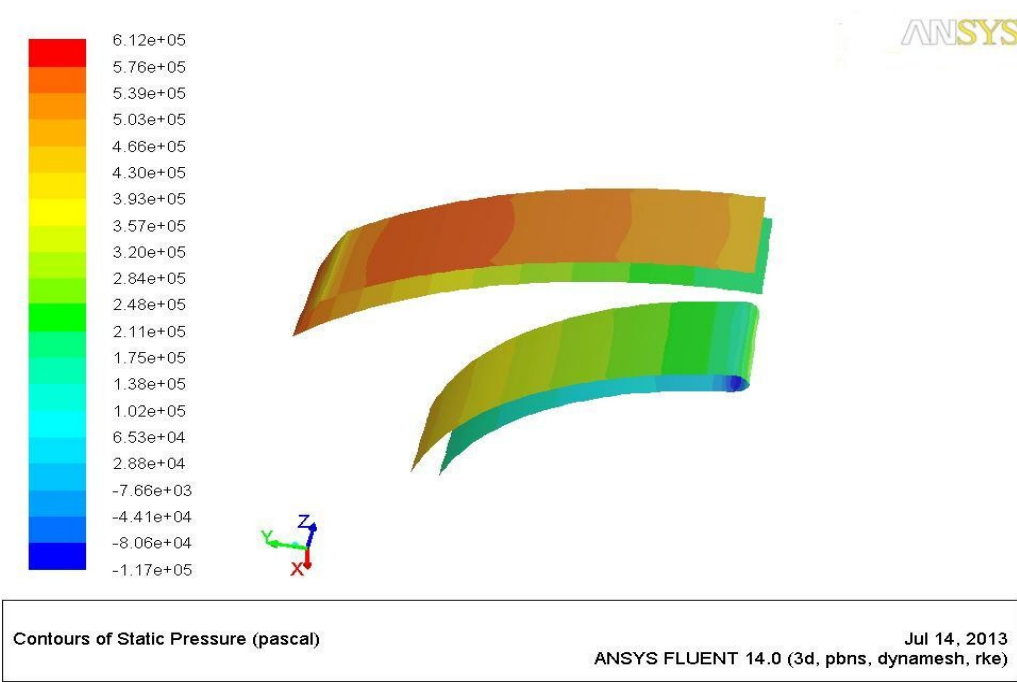

Figure(20) Static pressure contours in (Z-Y)plane of blade at 2400rpm 

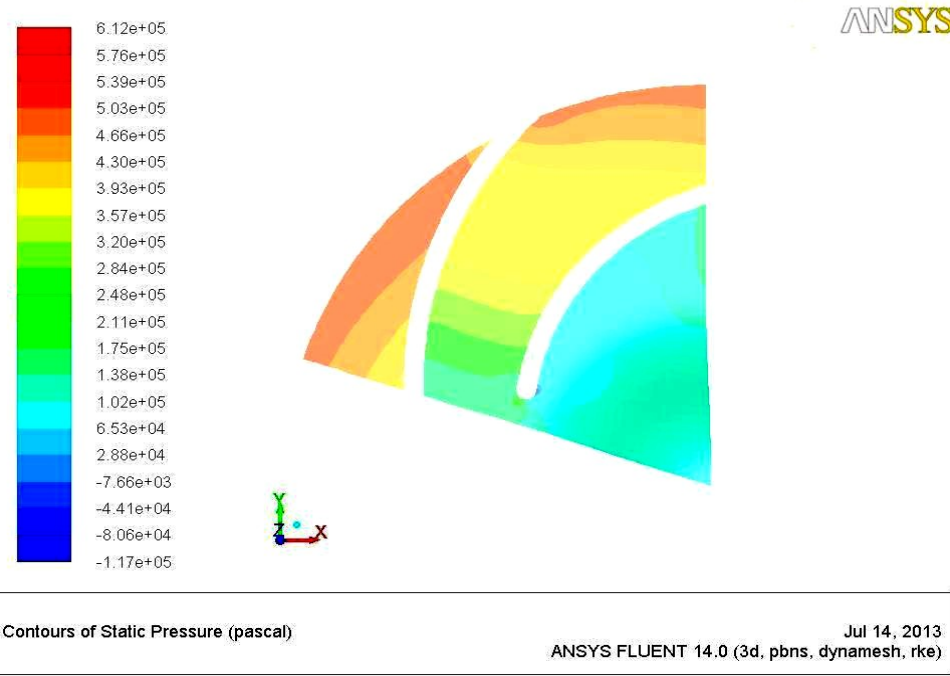

Contours of Static Pressure (pascal)

ANSYS FLUENT 14.0 (3d, pbns, dynamesh, rke)

Figure(21) Static pressure contours in (X-Y)plane of hub at 2400rpm

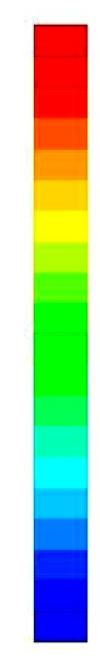

$$
\begin{aligned}
& 6.12 \mathrm{e}+05 \\
& 5.76 \mathrm{e}+05 \\
& 5.39 \mathrm{e}+05 \\
& 5.03 \mathrm{e}+05 \\
& 4.66 \mathrm{e}+05 \\
& 4.30 \mathrm{e}+05 \\
& 3.93 \mathrm{e}+05 \\
& 3.57 \mathrm{e}+05 \\
& 3.20 \mathrm{e}+05 \\
& 2.84 \mathrm{e}+05 \\
& 2.48 \mathrm{e}+05 \\
& 2.11 \mathrm{e}+05 \\
& 1.75 \mathrm{e}+05 \\
& 1.38 \mathrm{e}+05 \\
& 1.02 \mathrm{e}+05 \\
& 6.53 \mathrm{e}+04 \\
& 2.88 \mathrm{e}+04 \\
& -7.66 \mathrm{e}+03 \\
& -4.41 \mathrm{e}+04 \\
& -8.06 \mathrm{e}+04 \\
& \hline-1.17 \mathrm{e}
\end{aligned}
$$

$-1,17 e+05$

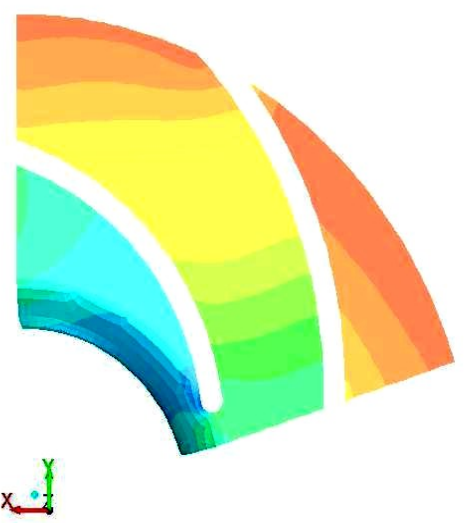

Contours of Static Pressure (pascal)

ANSYS FLUENT 14, 2013

Figure(22) Static pressure contours in (X-Y)plane of shroud at 2400rpm

\section{Conclusion}

The complex three dimensional internal flow field of the centrifugal pump is investigated by using numerical methods. This centrifugal pump simulation has permitted to study the internal flow static pressure distribution of the pump operating at variable rotational speed (under and over operation limits). The analysis of all the above results have led to the following conclusion:-

- The pressure increases gradually along the stream wise direction from minimum value at the suction side to the maximum value at leading edge.

- When the rotational speed increases the pressure at the suction side decreases .

- At the high rotational speed over the design point the pressure in the suction side became below the vaporization limits causes cavitation and wake region

- There are many types of pumps that have been studied and developed, including centrifugal pumps. Yet there is not one pump ideally suited for every application, there are still many issues that need to be improved to enhance performance and specific parameters for each case. 


\section{References}

[1] Dr. Jalal M. Jalil, Dr. Khalaf H. Ali, Dr. Hussein M. al-Yassiri, Three--Dimensional Numerical Study of Flow Characteristics Through a Centrifugal Pump, Al-Rafidain Engineering Vol.16 No.1 2008.

[2] C. H. Liu, C. Vafidis, and J. H.Whitelaw, "Flow characteristics of a centrifugal pump," ASME Journal of Fluids Engineering, vol. 116, no. 2, pp. 303-309, 1994.

[3] Zhou, W., Zhao, Z., Lee, T. S., and Winoto, S. H., Investigation of flow through centrifugal pump impellers using computational fluid dynamics, International Journal of Rotating Machinery, volume 9, pp 49-61.2003.

[4] A. Akhras, M. El Hajem, R. Morel, and J.-Y. Champagne, "Internal flow investigation of a centrifugal pump at the design point," Journal of Visualization, vol. 4, no. 1, pp. 91-98, 2001.

[5] N. Pedersen, P. S. Larsen, and C. B. Jacobsen, "Flow in a centrifugal pump impeller at design and off-design conditions- part I: particle image velocimetry (PIV) and laser Doppler velocimetry (LDV) measurements," ASME Journal of Fluids Engineering, vol. 125, no. 1, pp. 61-72, 2003.

[6] C. M. Heilmann and H. E. Siekmann, "Particle image velocimetry as CFD validation tool for flow field investigation in centrifugal pumps," in Proceedings of the 9th International Symposium on Transport Phenomena and Dynamics of Rotating Machinery (ISROMAC '02),Honolulu,Hawaii, USA, February 2002.

[7] K. Majidi and H. E. Siekmann, "Numerical calculation of secondary flow in pump volute and circular casings using 3D viscous flow techniques," International Journal of Rotating Machinery, vol. 6, no. 4, pp. 245-252, 2000.

[8] K. U. Ziegler, H. E. Gallus, and R. Niehuis, "A study on impeller-diffuser interaction-part I: influence on the performance," Journal of Turbomachinery, vol. 125, no. 1, pp. 173-182, 2003.

[9] F. Shi and H. Tsukamoto, "Numerical study of pressure fluctuations caused by impeller-diffuser interaction in a diffuser pump stage," ASME Journal of Fluids Engineering, vol. 123, no. 3, pp. 466-474, 2001.

[10] Y. K. P. Shum,C. S.Tan, andN. A. Cumpsty, "Impeller-diffuser interaction in a centrifugal compressor," Journal of Turbomachinery, vol. 122, no. 4, pp. 777-786, 2000.

[11] A. Akhras, M. El Hajem, J.-Y. Champagne, and R.Morel, "The flow rate influence on the interaction of a radial pump impeller and the diffuser," International Journal of Rotating Machinery, vol. 10, no. 4, pp. 309-317, 2004.

[12] S.-S. Hong and S.-H. Kang, "Flow at the centrifugal pump impeller exit with circumferential distortion of the outlet static pressure," ASME Journal of Fluids Engineering, vol. 126, no. 1, pp. 81-86, 2004.

[13] D. Hagelstein, K. Hillewaert, R. A. Van den Braembussche, A. Engeda, R. Keiper, andM. Rautenberg, "Experimental and numerical investigation of the flow in a centrifugal compressor volute," Journal of Turbomachinery, vol. 122, no. 1, pp. 2231,2000 .

[14] A. J. Stepanoff, Centrifugal and Axial Flow Pumps: Theory, Design and Application, Krieger, Melbourne, Fla, USA, 2nd edition, 1992.

[15] M.-J. Zhang, M. J. Pomfret, and C. M. Wong, "Three dimensional viscous flow simulation in a backswept centrifugal impeller at the design point," Computers and Fluids, vol. 25, no. 5, pp. 497-507, 1996.

[16] M.-J. Zhang, M. J. Pomfret, and C. M. Wong, "Performance prediction of a backswept centrifugal impeller at off-design point conditions," International Journal for Numerical Methods in Fluids, vol. 23, no. 9, pp. 883-895, 1996.

[17] R. K. Byskov, C. B. Jacobsen, and N. Pedersen, "Flow in a centrifugal pump impeller at design and off-design conditions- part II: large eddy simulations," ASME Journal of Fluids Engineering, vol. 125, no. 1, pp. 73-83, 2003.International IBPSA Conference, Rio de Janeiro, Brazil, pp. 1135-1141.

[18] F. Gu, A. Engeda, M. Cave, and J.-L. Di Liberti, "A numerical investigation on the volute/diffuser interaction due to the axial distortion at the impeller exit," ASME Journal of Fluids Engineering, vol. 123, no. 3, pp. 475-483, 2001. 